\title{
Comparisons of IgA response in saliva and colostrum against oral streptococci species
}

\section{Barbara Bellocchio BERTOLDO(a) Camilla Beatriz da SILVA(a) \\ Denise Bertulucci Rocha RODRIGUES(a) \\ Vinicius Rangel \\ GERALDO-MARTINS(a) \\ Virginia Paes Leme FERRIANI (b) \\ Ruchele Dias NOGUEIRA(b)}

(a) Universidade de Uberaba - Uniube, School of Dentistry, Department of Dentistry, Uberaba, MG, Brazil.

(b) Universidade de São Paulo - USP, Medical School of Ribeirao Preto, Department of Pediatrics, Ribeirão Preto, SP, Brazil.

Declaration of Interests: The authors certify that they have no commercial or associative interest that represents a conflict of interest in connection with the manuscript.

Corresponding Author:

Ruchele Dias Nogueira

E-mail: ruchele_nogueira@yahoo.com.br

https://doi.org/10.1590/1807-3107BOR-2017.vol31.0039

Submitted: Sep 16, 2015

Accepted for publication: Mar 27, 2017

Last revision: Apr 10, 2017
Abstract: The present study compared IgA specificity against oral streptococci in colostrum and saliva samples. Sixty-two mother-and-child pairs were included; samples of colostrum (C) and saliva (MS) were collected from the mothers and saliva samples were collected from babies (BS). The specificity of IgA against Streptococcus mutans and S. mitis were analyzed by western blot. Only $30 \%$ of babies' samples presented IgA reactivity to S. mutans, while 74 and $80 \%$ of MS and C, respectively, presented this response. IgA reactivity to $S$. mutans virulence antigens (Ag I/II, Gtf and GbpB) in positive samples showed differences between samples for Gtf and especially for GbpB ( $p<0.05)$, but responses to $\mathrm{Ag}$ I/II were similar ( $\mathrm{p}>0.05)$. The positive response of Gtf-reactive IgA was different between C $(90 \%)$ and MS $(58 \%)$ samples $(p<0.05)$, but did not differ from BS ( $p>0.05$ ). GbpB was the least detected, with 48 and $26 \%$ of $C$ and MS, and only $5 \%$ of BS samples presenting reactivity ( $p>0.05$ ). Eight percent of MS and C samples presented identical bands to $\mathrm{SM}$ in the same time-point. In conclusion, the differences of IgA response found between $\mathrm{C}$ and MS can be due to the different ways of stimulation, proliferation and transportation of $\operatorname{IgA}$ in those secretions. The colostrum has high levels of IgA against S. mutans virulence antigens, which could affect the installation and accumulation process of $S$. mutans, mainly by supplying anti-GbpB IgA to the neonate.

Keywords: Streptococcus mutans; Colostrum; Saliva; Immunoglobulin A.

\section{Introduction}

The oral cavity is an important access route into the human body for several microorganisms, some of which become residents that facilitate the adhesion and accumulation of other species, increasing the complexity of the oral microbial communities. Streptococcus mitis is the main bacteria that initially colonizes the oral cavity., ${ }^{1,2}$ After tooth eruption new species are more commonly found, such as Streptococcus mutans. ${ }^{3}$ However, these species may also be detected in predentate children highly exposed to $S$. mutans. ${ }^{4}$

Some major antigens expressed in the $S$. mutans cell surface, such as antigen I/II (Ag I/II), glucosyltransferase (Gtf) and glucan-binding protein $\mathrm{B}(\mathrm{GbpB})$, are involved in the ability of these microorganisms to adhere and accumulate in the oral biofilm, promoting the development of dental caries. ${ }^{5,6,7}$ Several studies have shown that the induction of 
specific antibodies against these antigens can confer protection against the development of dental caries in animal models. ${ }^{8}$ Some studies support the use of these antigens in clinical trials on vaccines against caries in older children and adults. ${ }^{9}$

The main immunoglobulin present in mucosal secretions is the secretory $\operatorname{Ig} \mathrm{A}(\operatorname{SIg} \mathrm{A})$, representing the first line of defense of the oral cavity. SIgA is associated to the oral microbiota control by reducing the adherence of bacteria on the mucosa and teeth. ${ }^{10}$ Previous prospective studies with 5- to 24-month-old children heavily exposed to $S$. mutans showed a complex pattern of salivary IgA reactivity to $S$. mutans antigens, ${ }^{11,12}$ suggesting that responses to virulence-associated antigens, especially against GbpB, may influence the ability of $S$. mutans to colonize the oral cavity. Thus, the salivary IgA response to $\mathrm{GbpB}$ can modulate the infection by $S$. mutans. Saliva from newborns with undetectable levels of S. mutans and detectable IgA levels, presented IgA reactivity to $\mathrm{Ag} \mathrm{I} / \mathrm{II}$ and $\mathrm{Gtf}$ in $16 \%$ of samples, but no reactivity to GbpB was detected. ${ }^{13}$ After 3 months, IgA reactivity to $\mathrm{Gtf}$ and $\mathrm{Ag} \mathrm{I} / \mathrm{II}$ was unchanged, but $7 \%$ of the children presented salivary $\operatorname{IgA}$ response to $\mathrm{GbpB}{ }^{14}$

Breastfeeding represents an important source of immune components for the mucosal membranes of neonates, especially by the mother-to-child transfer of SIgA, the main mediator of anti-bacterial activity in human colostrums. ${ }^{15,16}$ Several studies showed the passive protection conferred by breast milk against bacterial infections through binding mechanisms and also by covering the mucosal surfaces, preventing the adhesion and invasion of a large variety of pathogenic microorganisms. ${ }^{17,18}$

The IgA antibodies present in breast milk are directed against microbes and food proteins from the mother that the breastfeeding child may also have contact. ${ }^{19}$ This antigenic exposure of the gut associated lymphoid tissues (GALT) and upper respiratory tract tissues results in sensitized B-lymphocytes in those tissues via the circulation to mesenteric lymph nodes.

Previous studies showed that colostrum has detectable levels of IgA against all S. mutans antigens, although $\mathrm{GbpB}$ has been significantly less detected than other antigens. ${ }^{20}$ Therefore, colostrum provides to the neonate significant levels of specific IgA against S. mutans virulence, which can disrupt the installation and accumulation process of these microorganisms in the oral cavity ${ }^{20}$ and supply the immature mucosal immune system in early life, especially against GbpB, as anti-GpbB IgA is absent at birth. ${ }^{13,14}$

There is little information about the immune response during the early stages of $S$. mutans bacterial challenge and the role of IgA provided by breastfeeding against the installation of these bacteria. It is possible that some factors can affect the initial response of pioneer commensal species of the oral cavity, and influence the patterns of immune response and the susceptibility to colonization. In the present study, the levels of anti-S. mutans IgA and anti-S. mitis IgA were analyzed on saliva (MS) and colostrum (C) samples from mothers and in saliva samples from newborn babies (BS).

\section{Methodology}

\section{Study design}

A total of 62 pairs of mothers and newborns were enrolled in this study, after the mother's written consent for participation. The Ethical Committee of the Medical School of Ribeirao Preto, SP, Brazil, $13290 / 2012$, approved this study. Only healthy mothers submitted to a cesarean section within the previous 12 hours were included. Information about maternal and gestational background was obtained by interviewing the expectant mother at arrival in the maternity hospital. After birth, newborn's saliva samples were obtained. Collection of the mothers' samples (C and MS) occurred 12 hours after giving birth. Detectable levels of $S$. mutans were found in all MS samples, which were processed for immunoassay analysis.

\section{Collection of samples}

Samples of colostrum were collected manually and stored into sterile polypropylene Falcon tubes. After collection, the samples were transported to the laboratory, and centrifuged at 1,300 $\mathrm{g}$ to remove lipid components. Samples of whole non-stimulated saliva were collected using sterile polypropylene transfer pipettes. In newborns, collection saliva samples was performed at approximately 5 minutes after birth. A solution of 250 mM EDTA, pH 5.2 
(Sigma, St Louis, USA) was added to each sample prior to transporting it on ice to the laboratory for storage at $-80^{\circ} \mathrm{C}$ until analysis.

\section{Colostrum and saliva IgA reactivity against streptococcal antigens}

Total levels of IgA, IgM and IgG were determined in capture ELISA assays as previously described. ${ }^{11,20}$ Patterns of reactivity of salivary IgA antibody against S. mutans (UA159) and S. mitis (ATCC506) antigens were determined in western blot assays as previously described..$^{20}$ Sixteen micrograms of antigen extracts were loaded per lane, separated by $6 \%$ sodium dodecyl sulfate polyacrylamide gel electrophoresis, and transferred to nitrocellulose membranes. Membranes were washed and blocked overnight at $4^{\circ} \mathrm{C}$ (in Tris-buffered saline-Tween, $\mathrm{pH} 7.5,5 \%$ nonfat milk, Sigma). Incubations with diluted samples (normalized by the IgA concentration) were performed at room temperature for $2 \mathrm{~h}$. Membranes incubated with blocking buffer were used as negative controls, and membranes incubated with a standard saliva sample obtained from an adult whose pattern of reaction with antigen extracts had been previously measured were used as positive controls.

The secondary antibody was goat IgG anti-human IgA conjugated with horseradish peroxidase (Sigma, 1:4,000 dilutions). Antibody reactions were developed using an ECL system (GE Healthcare UK, Little Chalfont, United Kingdom). Immunoblots were incubated with ECL detection solution and then exposed to the same X-ray film for $5 \mathrm{~min}$. The developed X-ray films were scanned in a scanning densitometer (GE Healthcare) to analyze patterns of antigen recognition, including the number of reactive bands. A blank value was subtracted from the value of the reactive band.

\section{Statistical analysis}

Frequencies of children with IgA antibody specificities were compared by chi-square test. The mean number of IgA-reactive bands in antigen extracts was also determined and compared between samples with ANOVA. Associations between concentrations of specific IgA and patterns of antibody reactions between samples were tested by Pearson correlation analysis. A $p$-value of $<0.05$ was considered statistically significant.

\section{Results}

The mean concentrations of IgA in C, MS and BS were $2850.2( \pm 2567.2) ; 435.2( \pm 86.7)$ and $2.4( \pm 7.6) \mu \mathrm{g} / \mathrm{mL}$, respectively. There were no correlations in the levels of IgA between the samples $(p>0.05, r<0.23)$. The concentration of IgA in $\mathrm{C}$ and MS was significantly higher than in BS ( $p<0.05)$. No associations were found between immunoglobulin levels based on race, maternal age, oral health, type of birth and socioeconomic data ( $p>0.05)$.

The percentage of samples (C, MS and BS) with positive and negative IgA response to $S$. mutans and S. mitis is shown in Figure 1. The mean number of reactive bands to $S$. mutans and the frequency of positive response to the virulence antigens (Ag I/II, Gtf and $G b p B)$, in C ( $=50), M S(n=40)$ and BS $(n=16)$ samples presenting positive IgA response to $S$. mutans is shown in Table 1. The analysis in each group showed that the frequency of positive response to $\mathrm{Ag} \mathrm{I} / \mathrm{II}$ and Gtf were statistically higher than the negative (Table $1, p<0.05)$. Concerning GbpB, there was no difference between positive and negative detection in $\mathrm{C}$, but the number of negative IgA response was statistically higher than the positive in MS and BS ( $p<0.05$ ). The mean number of $S$. mitis reactive bands and the frequency of positive responses to $56 \mathrm{kDa}-\mathrm{Ag}$ of $S$. mitis in the samples is shown in Table 2. The number of IgA reactive bands to $S$. mitis was higher in $C$ and MS than in BS (Table 2).

The number of samples with IgA positive to $S$. mutans and S. mitis in BS was significantly lower than in C and MS ( $p<0.001$, Figure 1). Contrarily, the majority of $\mathrm{C}$ and MS samples were IgA-reactive to S. mutans and S. mitis, and did not differ statistically ( $p<0.05$, Figure 1). The mean number of IgA-reactive bands to $S$. mutans was significantly different between samples $(p<0.021)$, being higher in $C$, followed by MS and BS (Table 1). The mean number of IgA-reactive bands to $S$. mitis was similar between MS and C samples $(p=0.08)$ and lower in comparison with BS ( $p<0.006$, Table 2). 


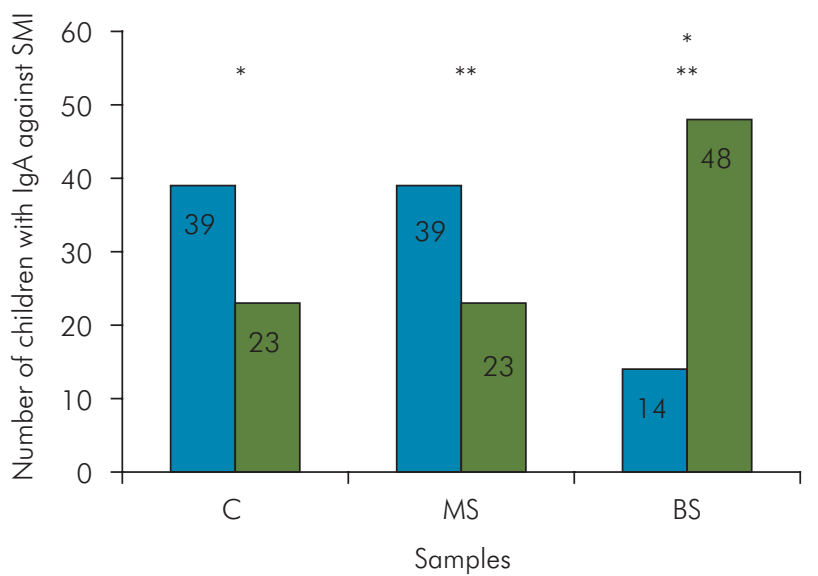

$\square \lg A$ reactive

$\lg A$ non-reactive

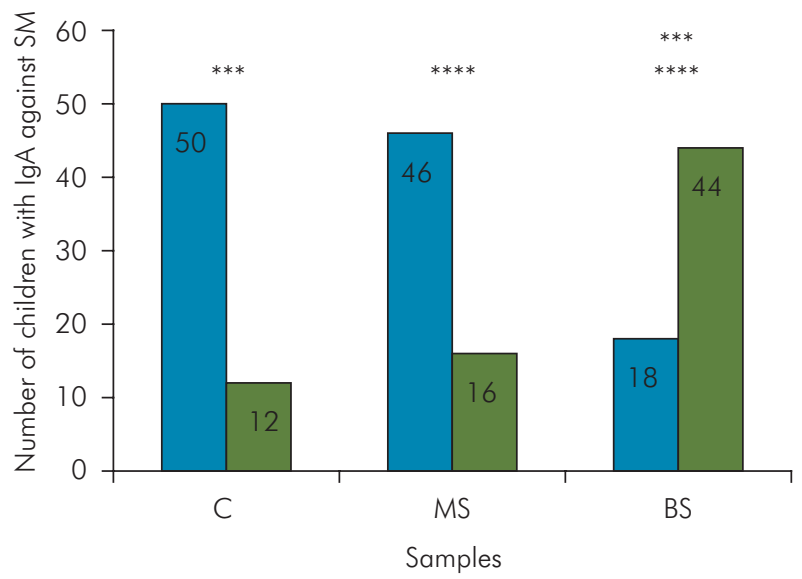

$\square \lg A$ reactive $\square \lg A$ non-reactive

* Chi-square, $p<0.01, q=23.2$

** Chi-square, $p<0.01, q=23.2$

$* * *$ Chi-Square, $p<0.01, q=33.3$

**** Chi-square, $p<0.01, \mathrm{q}=25.3$

Figure 1. Number of samples in C (colostrum), MS (maternal saliva) and BS (newborn saliva) with IgA reactive or not to SMI (Streptococcus mitis) and SM (S. mutans).

Table 1. Number and percentage of $S$. mutans positive samples in colostrum, maternal saliva and newborn saliva reactive or not to the $S$. mutans virulence antigens ( $\mathrm{Ag} \mathrm{I/II,} \mathrm{Gff} \mathrm{and} \mathrm{GbpB).} \mathrm{The} \mathrm{mean} \mathrm{and} \mathrm{standard} \mathrm{deviation} \mathrm{of} \mathrm{reactive} \mathrm{bands} \mathrm{in} \mathrm{each} \mathrm{tested} \mathrm{group} \mathrm{is} \mathrm{also} \mathrm{given.}$

\begin{tabular}{|c|c|c|c|c|c|c|}
\hline \multirow{3}{*}{ Variable } & \multicolumn{2}{|c|}{ Colostrum $(n=50)$} & \multicolumn{2}{|c|}{ Maternal saliva $(n=46)$} & \multicolumn{2}{|c|}{ Newborn saliva $(\mathrm{n}=18)$} \\
\hline & Yes & No & Yes & No & Yes & No \\
\hline & n (\%) & n (\%) & n (\%) & $n(\%)$ & n (\%) & n (\%) \\
\hline \multicolumn{7}{|l|}{ S. mutans antigens } \\
\hline $\mathrm{Ag} \mathrm{I/II}$ & (94.0) & $3(6.0)^{1}$ & (84.8) & $7(15.2)^{3}$ & (88.9) & $2(11.1)^{5}$ \\
\hline Gif & (96.0) & $2(4.0)^{2,7,8}$ & (78.3) & $(27.1)^{4,7}$ & $(66.7)$ & $6(33.3)^{6,8}$ \\
\hline GbpB & $(50.0)$ & $(50.0)^{1,2,9}$ & (36.9) & $(63.1)^{3,4,10}$ & $1(5.6)$ & $(94.4)^{5,6,9,9,10}$ \\
\hline Mean \pm SD of reactive antigens & $4.48 \pm 3.57^{11,12}$ & - & $2.69 \pm 2.49^{11,13}$ & - & $0.87 \pm 1.64^{12,13}$ & - \\
\hline
\end{tabular}

${ }^{1}$ Chi-square, $p<0.05, q=24.0 ;{ }^{2}$ Chi-square, $p<0.05, q=26.8 ;{ }^{3}$ Chi-square, $p<0.05, q=22.0 ;{ }^{4}$ Chi-square, $p<0.05$, $q=16.0 ;{ }^{5}$ Chi-square, $p<0.05, q=25.0 ;{ }^{6}$ Chi-square, $p<0.05, q=14.5 ;{ }^{7}$ Chi-square, $p<0.05, q=18.9 ;{ }^{8} \mathrm{Chi}$-square, $p<0.05, q=28.3 ;{ }^{9}$ Chi-square, $p<0.05, q=49.1 ;{ }^{10}$ Chi-square, $p<0.05, q=29.3 ;{ }^{11}$ ANOVA, $p=0.021 ;{ }^{12}$ ANOVA, $p=0.001 ;{ }^{13}$ ANOVA, $p=0.001$.

Table 2. Number and percentage of positive samples to S. mitis in colostrum, maternal saliva and newborn saliva reactive or not to the S. mitis antigen $(56 \mathrm{kDa}-\mathrm{Ag})$. The mean and standard deviation of reactive bands in each group is also given.

\begin{tabular}{lcccccc}
\hline & \multicolumn{2}{c}{ Colostrum $(n=39)$} & \multicolumn{2}{c}{ Maternal saliva $(\mathrm{n}=39)$} & \multicolumn{2}{c}{ Newborn saliva $(\mathrm{n}=14)$} \\
\cline { 2 - 6 } Variable & Yes & No & Yes & No & Yes & No \\
\cline { 2 - 6 } & $\mathrm{n}(\%)$ & $\mathrm{n}(\%)$ & $\mathrm{n}(\%)$ & $\mathrm{n}(\%)$ & $\mathrm{n}(\%)$ & $\mathrm{n}(\%)$ \\
\hline $\mathrm{SMl}$ antigens & $(89.7)$ & $4(10.3)$ & $(84.6)$ & $6(15.4)$ & $(85.7)$ & $2(14.3)$ \\
$\mathrm{kDa} \mathrm{Ag}$ & $1.68 \pm 2.07^{*}$ & - & $1.73 \pm 1.89^{*}$ & - & $0.71 \pm 1.77^{*}$ & - \\
Mean \pm SD of reactive antigens & & & & & \\
\hline
\end{tabular}

"ANOVA, $\mathrm{p}<0.05$. 


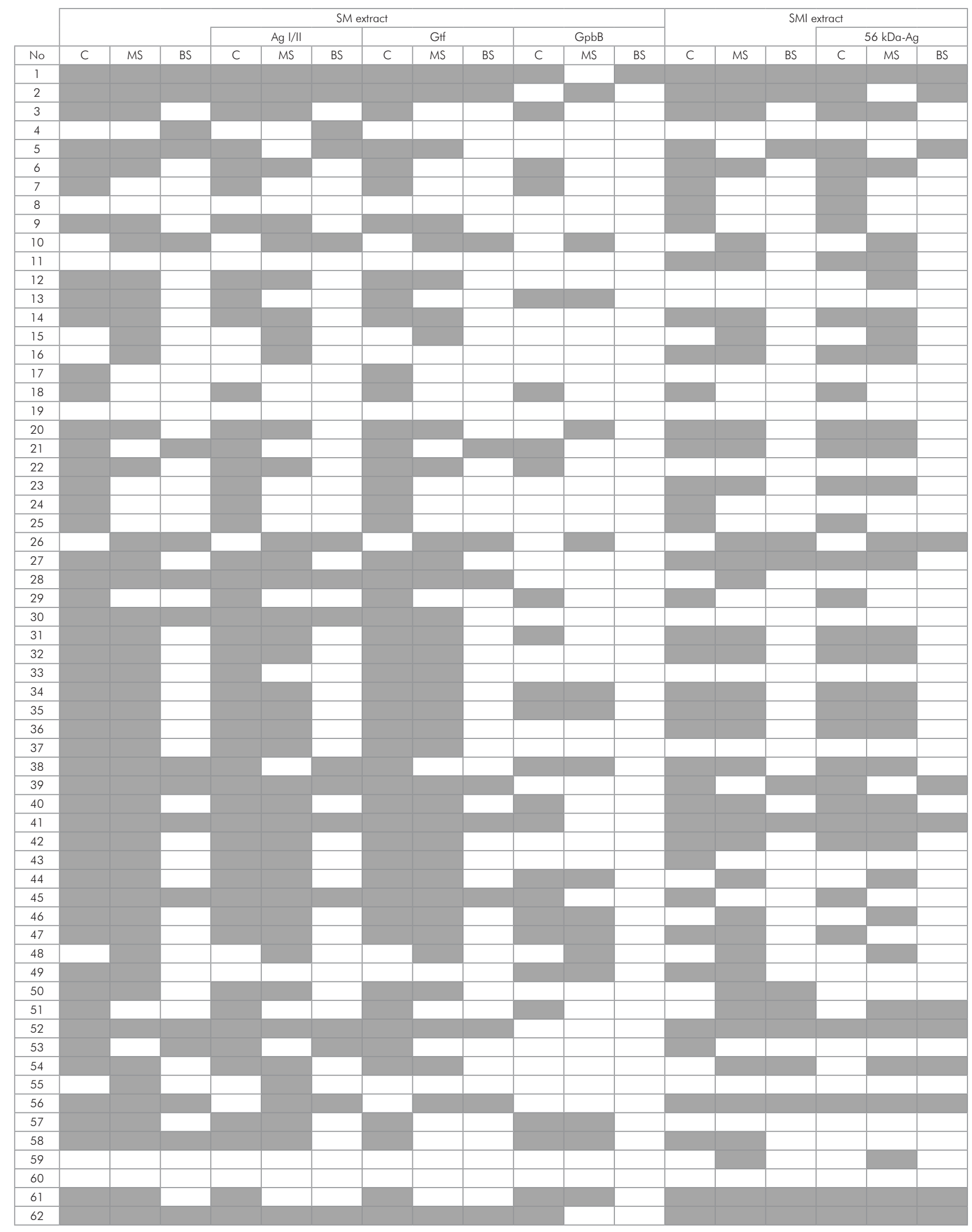

Figure 2. Schematic representation of positive (gray) and negative (white) lgA reactive to SMI (Streptococcus mitis) and SM (S. mutans) and their virulence antigens (Ag I/II, GH, GbpB) in C (colostrum), MS (maternal saliva) and BS (newborn saliva) in the 62 pairs of samples 
The positivity of samples with IgA reactive to $\mathrm{Gtf}$ was different between $\mathrm{C}$ and MS $(\mathrm{p}<0.001, \mathrm{q}=18.8)$ and between C and BS ( $<<0.001, q=28.9)$, with colostrum showing the greatest number of samples with Gtf-reactive IgA. GpbB-positive IgA was less frequent than other antigens in the samples $(\mathrm{p}<0.05)$, especially in BS, in which only $5.6 \%$ of samples were GbpB-positive, while 36.9 and $50.0 \%$ of MS and C, respectively, showed such response $(\mathrm{p}<0.05$ for between-group differences).

\section{Comparative analysis of IgA response patterns between groups}

Figure 2 shows a diagram of $\operatorname{IgA}$ responses to S. mutans and $S$. mitis and their virulence antigens in C, MS and BS. Examples of western blot from 3 samples of mothers (MS and $\mathrm{C}$ ) and their respective babies' saliva (BS) are illustrated in Figure 3. Pattern similarity analysis of IgA response to $S$. mutans between samples shows a positive correlation between positive response to $S$. mutans and Ag I/II $(\mathrm{p}<0.05, \mathrm{r}>0.79)$ and between S. mutans and Gtf $(\mathrm{p}<0.05, \mathrm{r}>0.69)$ in all samples. A positive correlation occurred between IgA response to $S$. mutans and GbpB in MS and C ( $p<0.05, r>0.36)$, but not in BS $(p>0.05)$. There was a positive correlation between $\mathrm{C}$ and $\mathrm{MS}$ in the IgA response to $S$. mutans $(p=0.03, r=0.27)$ and MS and BS in the IgA response to $\operatorname{Gtf}(\mathrm{p}=0.003, \mathrm{r}=0.36$ ).
The comparative analysis of IgA response patterns to $S$. mutans, in MS and C showed that only $8 \%$ of those samples presented identical bands in the same time-point, and $9.6 \%$ of samples did not present any band. C and MS samples presented some similarities in the response to $S$. mutans; for example, 48 pairs of $C$ and MS (77,4\%) presented the same response to $S$. mutans, which was not found when the comparisons were done between MS and BS (43,5\%), C and BS (38,7\%), and C, BS and MS (29,0\%).

The number of $C$ and MS that presented a similar positive response to Ag I/II and Gtf was higher than other antigens and samples $(p<0.05)$, because 29 pairs of those samples presented IgA response to Gtf and Ag I/II in the same time-point ( $<<0.05)$. In general, GbpB was different and less recognized by the samples, which was confirmed by the elevated number of sample pairs with a negative response to $\mathrm{GbpB}(\mathrm{p}<0.05)$ and a decreased number of pairs with similar IgA response to $\mathrm{GbpB}$ and other antigens in the same time-point $(\mathrm{p}<0.05)$.

\section{Discussion}

IgA concentration was significantly higher in colostrum than in maternal and newborn saliva, which is compatible with the type of secretion and maturation of the mucosal system. IgA antibodies reactive to $S$. mutans and $S$. mitis were found in most

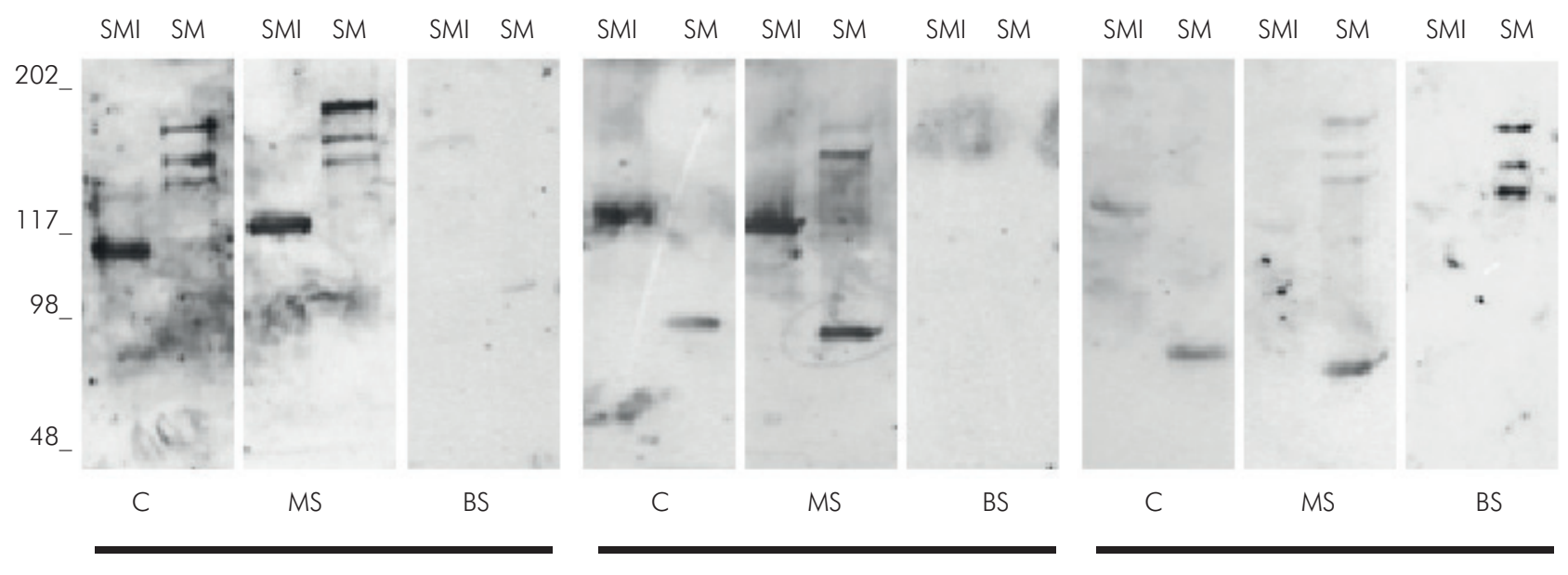

Figure 3. Patterns of IgA specificities against antigens from SMI (Streptococcus mitis) and SM (S. mutans) in C (colostrum), MS (maternal saliva) and BS (newborn saliva) in the 3 groups of samples. Standard molecular sizes (kDa) are indicated in left the immunoblots. 
of the MS and C samples (Figure 1). The analysis of reactive bands showed that colostrum has a more complex IgA response than MS or BS.

Although having an immature mucosal immune system, the newborns presented antibody production against oral streptococcal colonizers, as found by Borges et al. ${ }^{14}$ Since saliva collection was performed before starting breastfeeding, the presence of IgA in babies' saliva supports the hypothesis that oral bacterial antigens can be transferred from mother to child via the umbilical cord blood and/or through the amniotic fluid. Past studies suggest that during the intrauterine life there is an efflux of commensal bacteria from the mother to the child. ${ }^{23}$ The presence of Enterococcus, Staphylococcus epidermidis and Streptococcus sanguinis was identified in cord blood samples ${ }^{24}$ and these species are frequently detected during the first days of life, generally regarded as commensal organisms in healthy children. ${ }^{23,24}$ Thus, the bacteria detected in the babies' saliva could have been delivered to the fetus in utero and thereby stimulating the development of the mucosal immune system.

The analysis of $S$. mutans-specific IgA antigens showed that the majority of samples with positive response to $S$. mutans presented IgA response against Ag I/II and Gtf, which was found in colostrum samples ${ }^{20}$ and saliva from children at birth ${ }^{14}$ at three months ${ }^{14}$ and 5-11 months of age, ${ }^{12}$ regardless of S. mutans colonization. On the other hand, many samples had a negative IgA response to $\mathrm{GbpB}$, especially in the salivary samples. The $S$. mutans virulence is related, among other mechanisms, to its ability to synthesize $\mathrm{GbpB}$, a heterogeneous group of proteins that promote cell adhesion to the tooth surface..$^{25}$ Thus, studies on the natural immune response against this protein can provide evidence of its importance and immunogenic behavior, especially considering that the positive response of $\operatorname{IgA}$ to $\mathrm{GbpB}$ in saliva samples was more commonly found in children not colonized by $S$. mutans. ${ }^{12}$

It is critical to investigate the transfer of antibodies from the mother to the newborn by breastfeeding as an important way of fighting several infectious challenges. Recent studies show that colostrum may supplement the lack of antibodies in the newborn, since colostrum have high levels of IgA against S. mutans antigens. ${ }^{20}$ Here, the differences found in the frequency and specificity of IgA between $\mathrm{C}$ and BS support the importance of breastfeeding against oral colonization early in life. Clearly, the high levels of IgA specific to S. mutans antigens in colostrum can address the lack of antibodies in the newborn's saliva, especially against GbpB, a protein which is absent in saliva of the absolute majority of babies' saliva samples. However, to attest the function and protection of colostrum in the prevention of caries disease, it is necessary to study the influence of colostrum in the $S$. mutans biofilm formation.

Little is known about the role of $S$. mutans antigens in the immune system of mucosal membranes, and the results of this study highlight some important points. First, the presence of antibodies against S. mutans in colostrum and saliva of mothers is related to the presence of the $S$. mutans colonizing the oral cavity. In both samples, there was a positive correlation between the IgA responses to $S$. mutans, showing that the stimulation pathways are the same (by oral colonization).

Assuming that the stimulation is by intra-uterine route, $\mathrm{GbpB}$ protein is not transferred and does not stimulate the immune system of the fetus, which justifies a smaller amount of salivary antibodies against $\mathrm{GbpB}$. With time, the baby is exposed to S. mutans, and IgA reactive to $\mathrm{GbpB}$ antibodies become detectable at 3 months, as described by Borges et al. ${ }^{14}$ At 6 months of age, this reactivity has an important modulatory action on infection, as reported by Nogueira et al. ${ }^{12}$

In summary, the complexity of IgA in colostrum and saliva of mothers is similar and suggest a common pathway, although the concentration of Igs in colostrum is significantly higher. In newborn's saliva, the levels of IgA are low especially against GbpB, which strengthens the importance of breastfeeding in controlling early infections by $S$. mutans.

\section{Acknowledgments}

This study was supported by Conselho Nacional de Pesquisa (CNPq), proc. 472928/2007-4. 
- Comparisons of IgA response in saliva and colostrum against oral streptococci species

\section{References}

1. Hohwy J, Reinholdt J, Kilian M. Population dynamics of Streptococcus mitis in its natural habitat. Infect Immun. 2001;69(10):6055-63. https://doi.org/10.1128/IAI.69.10.6055-6063.2001

2. Seow WK, Lam JH, Tsang AK, Holcombe T, Bird PS. Oral Streptococcus species in pre-term and full-term children - a longitudinal study. Int J Paediatr Dent. 2009;19(6):406-11. https://doi.org/10.1111/j.1365-263X.2009.01003.x

3. Caufield PW, Cutter GR, Dasanayake AP. Initial acquisition of mutans streptococci by infants: evidence for a discrete window of infectivity. J Dent Res. 1993;72(1):37-45. https://doi.org/10.1177/00220345930720010501

4. Alves AC, Nogueira RD, Stipp RN, Pampolini F, Moraes AB, Gonçalves RB et al. Prospective study of potential sources of Streptococcus mutans transmission in nursery school children. J Med Microbiol. 2009;8(4):476-8. https://doi.org/10.1099/jmm.0.005777-0

5. Lee SF, Progulske-Fox A, Bleiweis AS. Molecular cloning and expression of a Streptococcus mutans major surface protein antigen. $\mathrm{Pl}(\mathrm{I} / \mathrm{II})$, in Escherichia coli. Infect Immun. 1998;56(8):2114-9.

6. Smith DJ, Taubman MA. Experimental immunization of rats with a Streptococcus mutans 59-kilodalton glucan-binding protein protects against dental caries. Infect Immun. 1996;64(8):3069-73.

7. Yamashita Y, Bowen WH, Burne RA, Kuramitsu HK. Role of the Streptococcus mutans gtf genes in caries induction in the specific-pathogen-free rat model. Infect Immun. 1993;61(9):7-11.

8. Koga T, Oho T, Shimazaki Y, Nakano Y. Immunization against dental caries. Vaccine. 2002;20(16):2027-44. https://doi.org/10.1016/S0264-410X(02)00047-6

9. Childers NK, Tong G, Mitchell S, Kirk K, Russell MW, Michalek SM. A controlled clinical study of the effect of nasal immunization with a Streptococcus mutans antigen alone or incorporated into lipossomes on induction of immune responses. Infect Immun. 1999;67(2):618-23.

10. Clapp DW. Developmental regulation of the immune system. Semin Perinatol. 2006;30(2):69-72. https://doi.org/10.1053/i.semperi.2006.02.004

11. Nogueira RD, Alves AC, Napimoga MH, Smith DJ, Mattos-Graner RO. Characterization of salivary immunoglobulin A responses in children heavily exposed to the oral bacterium Streptococcus mutans: influence of specific antigen recognition in infection. Infect Immun. 2005;73(9):5675-84. https://doi.org/10.1128/IAl.73.9.5675-5684.2005
12. Nogueira RD, Alves AC, King WF, Gonçalves RB, Höfling JF, Smith DJ. Age-specific salivary immunoglobulin A response to Streptococcus mutans GbpB. Clin. Vaccine Immunol. 2007;14(6):804-7. https://doi.org/10.1128/CVI.00098-07

13. Nogueira RD, Sesso ML, Borges MC, Mattos-Graner RO, Smith DJ, Ferriani VP. Salivary IgA antibody responses to Streptococcus mitis and Streptococcus mutans in preterm and fullterm newborn children. Arch Oral Biol. 2012;57(6):647-53. https://doi.org/10.1016/i.archoralbio.2011.11.011

14. Borges MC, Sesso ML, Roberti LR, Oliveira MA, Nogueira RD, Geraldo-Martins VR et al. Salivary antibody response to streptococci in preterm and fullterm children: a prospective study. Arch Oral Biol. 2015;60(1):116-25 https://doi.org/10.1016/i.archoralbio.2014.08.003

15. Pribylova J, Krausova K, Kocourkova I, Rossmann P, Klimesova K, Kverka M et al. Colostrum of healthy mothers contains broad spectrum of secretory $\lg \mathrm{A}$ autoantibodies. J Clin Immunol. 2012;32(6):1372-80. https://doi.org/10.1007/s10875-012-9733-9

16. Ovono Abessolo F, Essomo Owono Megne-Mbo M, Ategbo S, N'negue MA, Lendoye E, Mvé Abaga R et al. [Profile of immunoglobulins $A, G$, and $M$ during breast milk maturation in a tropical area (Gabon)]. Sante. 2011;21(1):15-9. French. https://doi.org/10.1684/san.2011.0230

17. Bertoldo BB, Corrêa NF, Nogueira RD. Influência do aleitamento materno no estabelecimento de microrganismos cariogênico e desenvolvimento de cárie. Unopar Cient Cienc Biol Saúde. 2012;15(4):1-8. https://doi.org/10.17921/2447-8938.2013v15n4p\%25p

18. Van de Perre P. Transfer of antibody via mother's milk. Vaccine. 2003;21(24):3374-6. https://doi.org/10.1016/S0264-410X(03)00336-0

19. Tomicić S, Johansson G, Voor T, Björkstén B, Böttcher MF, Jenmalm MC. Breast milk cytokine and IgA composition differ in Estonian and Swedish mothers-relationship to microbial pressure and infant allergy. Pediatr Res. 2010;68(4):330-4. https://doi.org/10.1203/PDR.0b013e3181ee049d

20. Petrechen LN, Zago FH, Sesso ML, Bertoldo BB, Silva CB, Azevedo KP. Levels and complexity of $\lg A$ antibody against oral bacteria in samples of human colostrums. Immunobiol. 2014;220(1):142-6. https://doi.org/10.1016/j.imbio.2014.08.009

21. Mickleson KN, Moriarty KM. Immunoglobulin levels in human colostrum and milk.

J Pediatr Gastroenterol Nutr. 1982;1 (3):381-4 . https://doi.org/10.1097/00005176-198201030-00018 
22. Wan AK, Seow WK, Purdie DM, Bird PS, Walsh LJ, Tudehope DI. Immunoglobulins in saliva of preterm and full-term infants: a longitudinal study from 0-18 months of age. Oral Microbiol Immunol, 2003;18(2):72-8. https://doi.org/10.1034/j.1399-302X.2003.00044.x

23. Martín R, Langa S, Reviriego C, Jimínez E, Marín ML, Xaus J. Human milk is a source of lactic acid bacteria for the infant gut. J Pediatr. 2003;143(6):754-8. https://doi.org/10.1016/i.jpeds.2003.09.028
24. Jiménez E, Fernández L, Marín ML, Martín R, Odriozola JM, Nueno-Palop $C$ et al. Isolation of commensal bacteria from umbilical cord blood of healthy neonates born by cesarean section. Curr Microbiol. 2005;51(4):270-4. https://doi.org/10.1007/s00284-005-0020-3

25. Hoshino T, Fujiwara T, Kawabata S. Evolution of cariogenic character in Streptococcus mutans: horizontal transmission of glycosyl hydrolase family 70 genes. Sci Rep. 2012;2:518. https://doi.org/10.1038/srep00518 